\title{
CHEMICAL, CLINICAL, AND IMMUNOLOGICAL STUDIES ON THE PRODUCTS OF HUMAN PLASMA FRACTIONATION. XXXV. THE PERSISTENCE OF FIBRIN FILM IN TISSUE AND ITS MODIFICATION BY HEAT TREATMENT ${ }^{1,2}$
}

\author{
By PETER R. MORRISON AND MARCUS SINGER
}

\author{
(From the Departments of Physical Chemistry and Anatomy, Harvard Medical School, Boston)
}

(Received for publication February 7, 1947)

The fractionation of human plasma into its component proteins (1) has made possible the preparation of several new plastic materials $(2,3)$. These materials, fibrin film and fibrinogen plastic, are formed from native homologous proteins and have found application in surgery because of their favorable mechanical properties and their faculty of being absorbed in the body with almost no irritative reaction. The rate of absorption and the persistence time, however, depend on the modifying treatment to which they have been exposed. In its application as a dural substitute (4), thus far its most extensive clinical use, heat-sterilized fibrin film persists for periods of several months. Observations on unheated fibrin film, on the other hand, have shown much more rapid absorption. For certain uses, such as in peripheral nerve suture (5) or in tendon repair, neither of these extremes seemed desirable; the heat-sterilized film evoked too great tissue reaction, while the untreated film disappeared too rapidly to be effective.

The present study was undertaken to obtain exact information on the rate of absorption of fibrin films which had been exposed to varying degrees of heat treatment and to find, if possible, conditions which would allow fixing the persistence time to meet a given surgical need. Some quantitative measurements on the extent of gross tissue reaction to the implant are also reported. Observation on the histological sequence involved in the absorption

\footnotetext{
1 This work has been carried out under contract, recommended by the Committee on Medical Research, between the Office of Scientific Research and Development and Harvard University.

2 This paper is Number 58 in the series "Studies on the Plasma Proteins" from the Harvard Medical School, Boston, Massachusetts, on products developed by the Department of Physical Chemistry from blood collected by the American Red Cross.
}

of heat-sterilized films (6) and plastics ${ }^{3}$ have already been made by Bailey, and a preliminary report of some of these findings has already been presented (7). Although primarily concerned with the absorption of fibrin films, some observations on the absorption of implanted fibrinogen plastic, and the tissue responses to its presence, are also reported.

Measurements were also made to determine the resistance of variously heated fibrin films to tryptic digestion. Proteolytic digestion has previously been used $(8,9)$ as a measure of the absorbability of surgical gut. Although the 2 processes are qualitatively similar, important quantitative differences may obtain. The absorption of fibrin film in vivo is compared to its tryptic digestion in vitro.

\section{MATERIALS AND METHODS}

Fibrin film was prepared from human fibrinogen and thrombin (10). Some films were made aseptically from solutions which had been previously sterilized by filtration; in others, unsterile materials were used and the films were subsequently sterilized by heat treatment. Fibrinogen plastic containing 67 per cent of glycerol as plasticizer was prepared by heating at $100^{\circ} \mathrm{C}$. under pressure for 15 minutes. The types of material used, according to thickness and extent of heat treatment, were as follows :

A. Aseptically prepared fibrin films of 4,7 , and $11 \mathrm{mgm}$. fibrin per sq. $\mathrm{cm}$.

1. Unmodified.

2. Heated in glycerol at $100^{\circ} \mathrm{C}$. for periods of $1 / 2$ 1,3 , and 10 minutes.

B. Heat-sterilized fibrin films * $17 \mathrm{mgm}$. fibrin per sq. $\mathrm{cm}$.

3 Bailey, Ford, and Hawn. A report to the Proctor Fund, Harvard University, September 1, 1942. This study of the histological response to a series of implanted fibrinogen plastics was begun early in 1941.

4 Fibrin film was at first sterilized in this manner but it was subsequently found possible to sterilize it by direct 
1. Autoclaved under glycerol for 15 minutes at $120^{\circ} \mathrm{C}$.

2. Heated in glycerol for 1 minute at $155^{\circ} \mathrm{C}$.

C. Fibrinogen plastic of $13 \mathrm{mgm}$. dry weight per sq. $\mathrm{cm}$., sterilized by autoclaving under glycerol for 15 minutes at $120^{\circ} \mathrm{C}$.

Squares $(1 \mathrm{~cm}$. by $1 \mathrm{~cm}$.) of these materials were implanted in rabbits both subdermally over the femorococcygeal muscle and intermuscularly between that muscle and the adductor group. The implants were made in normal and burned ${ }^{b}$ tissues; however, results proved

exposure to steam $(3,11)$ and material for clinical use is now prepared in this manner. In use as a dural substitute the persistence time and tissue reaction to the 2 types are similar (4).

5 In one series implants were introduced into areas which had been injured by burning in order to clarify the observation that fibrin films used therapeutically on burns often disintegrated much more rapidly than in other situations. Note reference (12).

\section{Absorption of Aseptically Prepared Fibrin Film}
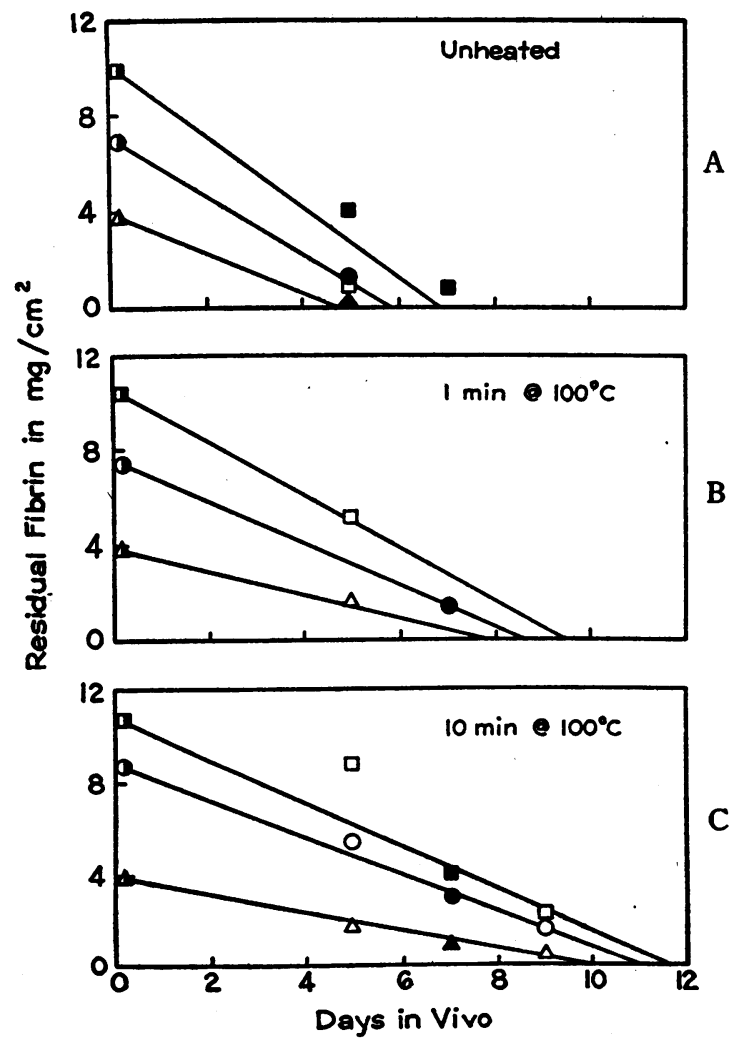

Fig. 1. The Absorption of Unheated and Moderately Heated Fibrin Films

The symbols represent different initial film weights. Open symbols indicate subdermal implantation; closed symbols, intermuscular.
Absorption of Heat Sterilized Films eslastics

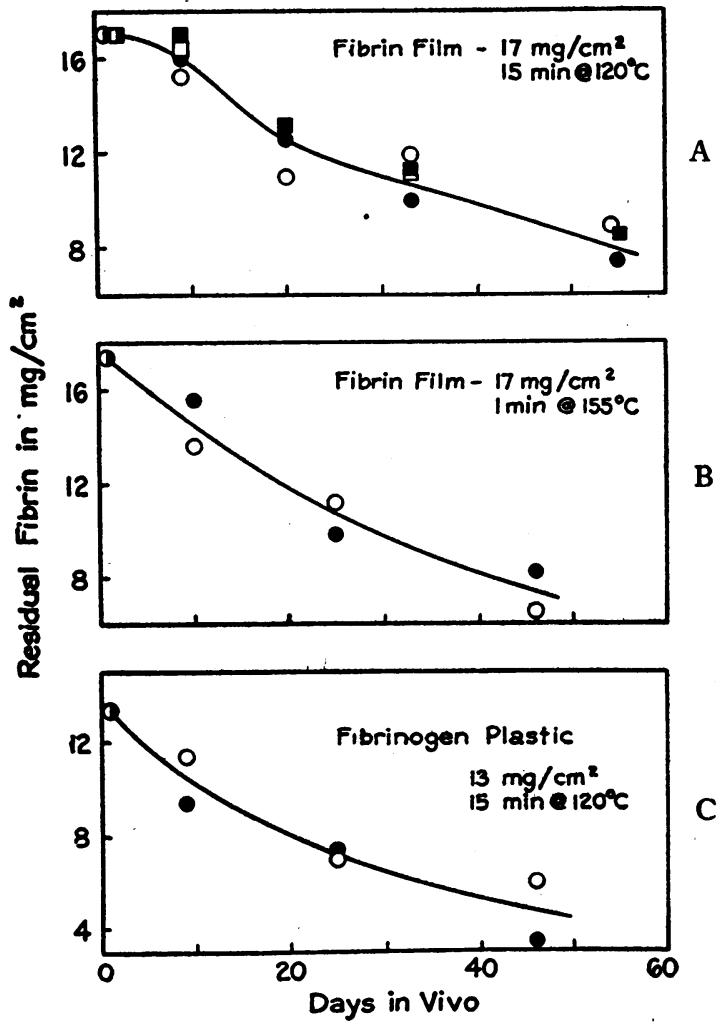

Fig. 2. The Absorption of Heat-Sterilized Films and Plastics

Open circles, subdermal implantation; closed circles, intermuscular. Squares indicate implantation in burned tissues.

identical in both cases. Furthermore, it was observed that absorption proceeded similarly irrespective of whether implantation was subdermal or intermuscular. Consequently, the observations on these 2 situations are not treated separately, but have been combined in the discussion of results.

The implants were anchored at each corner with a loop of silk thread. They were removed at intervals and the residual fibrin was determined gravimetrically by soaking in distilled water, drying at $110^{\circ} \mathrm{C}$, and weighing to 0.1 to $0.2 \mathrm{mgm}$. There was a variability of 0.2 to $0.5 \mathrm{mgm}$. in the initial weight of individual pieces and the initial weight was taken as the average of a series of 6 squares. In the late stages of absorption the difficulty in locating and removing the remaining fragments of fibrin introduced an additional error.

In measuring tryptic digestion a 1 per cent solution of a commercial trypsin in phosphate buffer of $\mathrm{pH} 7.0$ and ionic strength of 0.15 was clarified by centrifugation and filtration. It was allowed to act at $38^{\circ} \mathrm{C}$. for various lengths of time, and the residual fibrin was determined as 
above. This trypsin (Cenco) required twice as long as standard trypsin (U.S.P.) to digest heat-sterilized fibrin film. Measurements of tensile strength were made using a simple spring balance. Pieces of film 1 by $6 \mathrm{~cm}$. and of a single weight, $16 \mathrm{mgm}$. per $\mathrm{cm}^{2}$., were used in these experiments.

\section{RESULTS}

The experimental results are summarized in Figures 1 and 2 and show the progressive absorption of the fibrin following implantation. The unmodified films are absorbed most rapidly and the heat-sterilized films most slowly; the moderately heated films lie between these extremes. In presenting the data on unmodified and moderately heated films the course of absorption has been represented by a straight line whose slope gives the absorption rate and whose intercept is the persistence time. This follows the convention of Jenkins and Hrdina (13) in their studies on the absorption of surgical gut. It should be noted, however, that histological examination has revealed small fragments of fibrin after considerably longer periods than the persistence time as indicated by this method (5). The course of absorp- tion of the heat-sterilized materials cannot be represented by a straight line since the absorption rate clearly falls off with time.

Unmodified film. Complete absorption of all the unmodified films $\left(4,7\right.$, and $11 \mathrm{mgm}$. per $\left.\mathrm{cm}^{2}\right)$ occurs in less than 9 days (Figure 1A). The absorption rates vary from 0.85 to $1.45 \mathrm{mgm}$. per day with increasing thickness of film. Even at the earliest time of examination ( 5 days) the film was very weak and could not be removed in a single piece.

Heat-sterilized film. The absorption curves shown by fibrin film heated for 15 minutes at $120^{\circ}$ C. and for 1 minute at $155^{\circ} \mathrm{C}$. (Figures $2 \mathrm{~A}$ and $\mathrm{B}$ ) are very similar. They have initial slopes (or absorption rates) of 0.24 to $0.35 \mathrm{mgm}$. per day but level off to 0.12 to $0.14 \mathrm{mgm}$. per day after 40 days in the animal. In the single animal examined after a longer period (81 days) considerable amounts of film still remained. In contrast to unmodified film, heat-sterilized film retained more of its tensile strength and could usually be removed in a single piece.

Effect of Heat Treatment on the Absorption of Fibrin Film

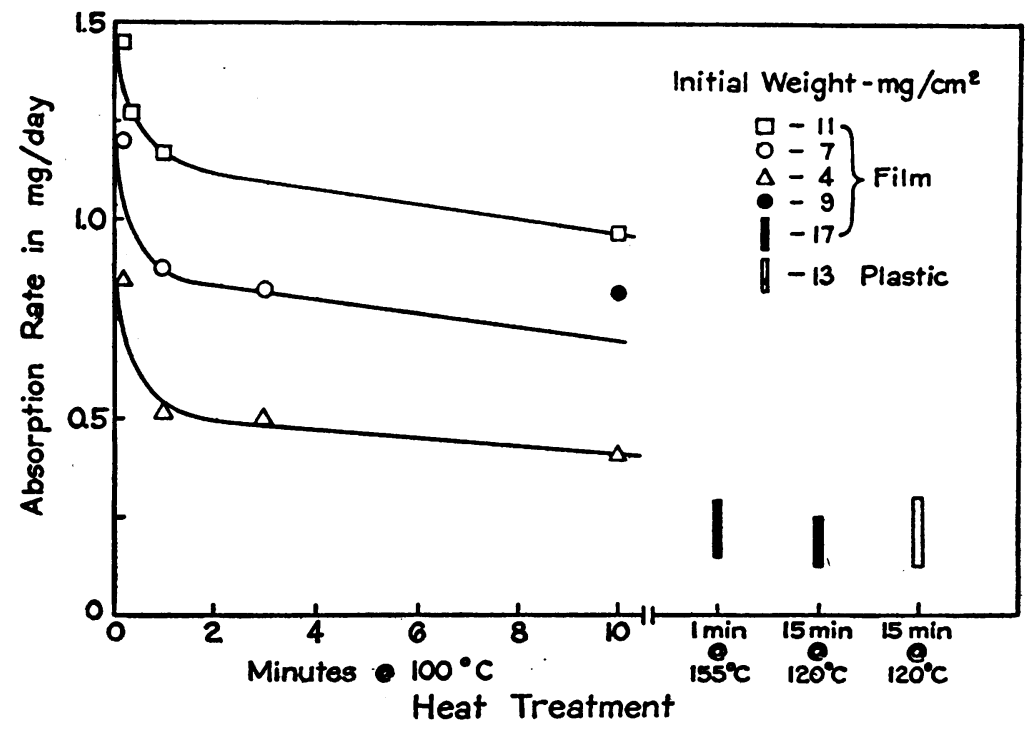

Fig. 3. The Effect of Heat Treatment on the Absorption of Fibrin Film

Ordinate, rate of absorption in mgm. of fibrin per day (i.e., the slopes of the curves in Figures 1 and 2); abscissa, degree of heat treatment. In the strongly heated materials. whose absorption rate changed with time the range of values has been shown by the height of the symbol. 
Moderately heated film. The course of absorption of films subjected to moderate heat treatment (Figures $1 \mathrm{~B}$ and $1 \mathrm{C}$ ) was intermediate to those of the unmodified and the heat-sterilized films. Although persisting for longer times, films heated at $100^{\circ} \mathrm{C}$. for $1 / 3,1$, or 3 minutes resembled the unheated films in their fragmentation and rapid loss of tensile strength. On the other hand, those heated for 10 minutes behaved more like the heatsterilized films and retained their original form during most of the absorption period. The effect of heat treatment on the absorption rates of these films has been summarized in Figure 3 and it may be seen that the 3- and 10-minute films have quite comparable absorption rates, roughly $1 / 2$ that of the unmodified film, despite this marked difference in mechanical properties.

Tissue reaction to the implant. In the unmodified and moderately heated films, with their shorter persistence times, gross encapsulation by fibrous connective tissue could not be detected. In contrast, the absorption of heat-sterilized films, with their extended persistence times, always was accompanied by the development of a firm fibrous capsule. Although undoubtedly preceded by a a histological sequence of events $(5,6)$, this cap- sule was grossly evident as a well-organized structure only after 10 days following implantation. It was observed to increase in thickness during the following 20 days. The capsule was easily separated from the surrounding loose connective tissue and completely enveloped the film. The film, in turn, lay free within the capsule and could usually be removed in a single piece. Internally the capsule was characterized by a shiny smooth surface having the appearance of a serous lining. Since it could be so easily separated from the surrounding tissue and the enclosed film, quantitive estimates of the response of the host to the foreign body could be obtained. The dry weight of the capsule was measured in a manner similar to that used for the film.

Figure 4 pictures the progressive growth of the capsule. The curve is characterized by a rapid increase during the 10- to 25-day period followed by a leveling off at about $10 \mathrm{mgm}$. during the succeeding 30 days. This value may be more fully appreciated when it is compared to the dry weight of the connective tissue sheet normally occurring at the implantation site which is of the order of 1 mgm. per $\mathrm{cm}^{2}$. A single pair of. measurements after 81 days suggests that there is a reduction in

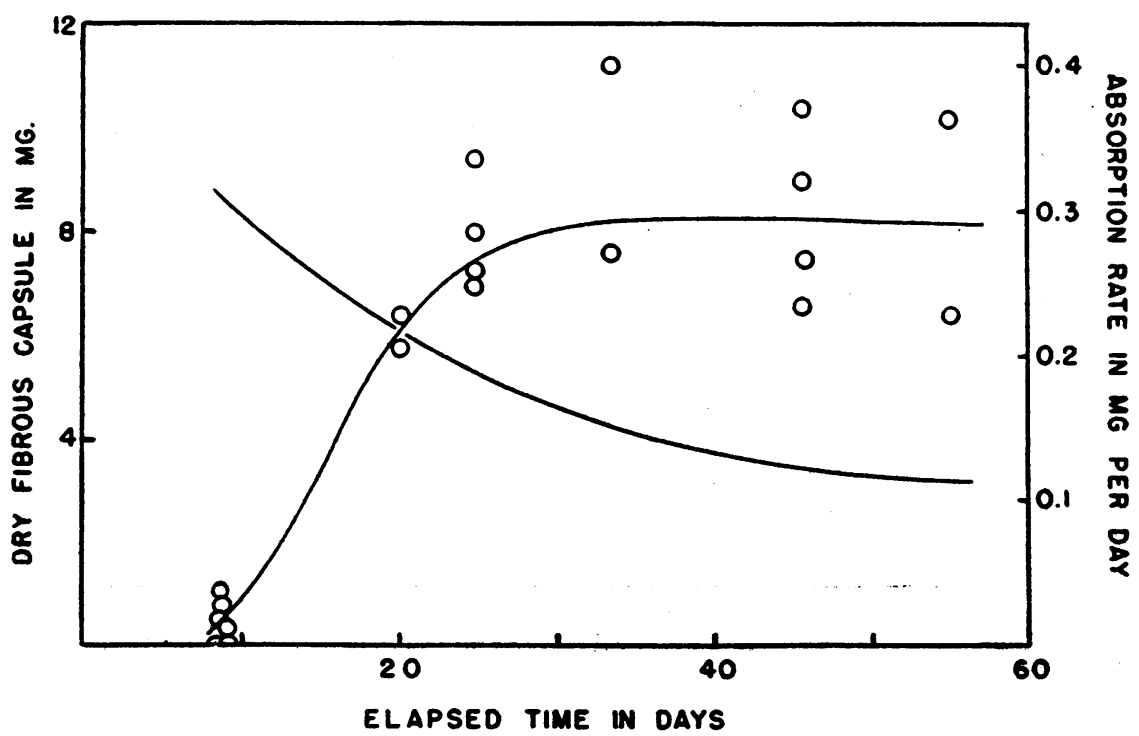

Fig. 4. The Encapsulation of Implanted Heat-Sterifized Fibrin Film as a Function of Time

Points represent the dry weight of the capsule surrounding a $1 \mathrm{~cm}$. by $1 \mathrm{~cm}$. piece of film. The descending curve which shows the falling off in the rate of absorption with time derives from the slopes of the average curves in Figure 2. 


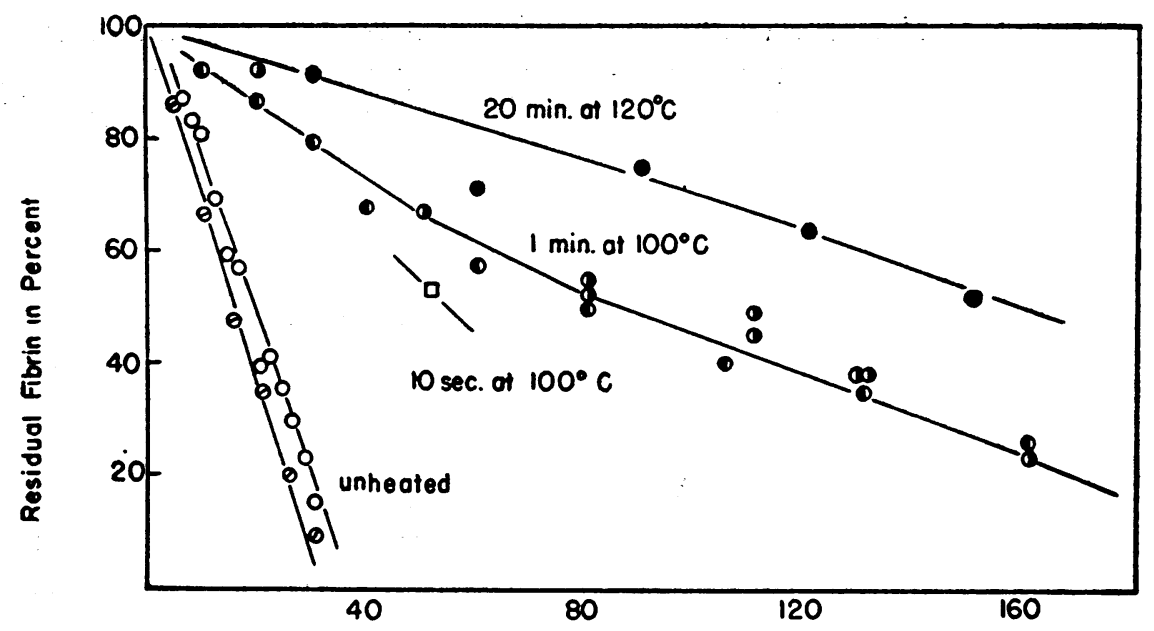

Elopsed Time in Minutes

Fig. 5. The Course of Tryptic Digestion in Variously Heated Fibrin Films

Symbols represent different heat treatments as indicated. Temperature, $38^{\circ} \mathrm{C}$.; $\mathrm{pH}, 6.9$; ionic strength, 0.15 ; fibrin film, $12 \mathrm{mgm}$. per sq. $\mathrm{cm}$., plasticizer not removed before heating.

size of the capsule as absorption of the fibrin nears completion. In these 2 instances the weights were 2.6 and $6.4 \mathrm{mgm}$. or about $1 / 2$ the average value between 30 and 50 days.

Fibrinogen plastic. The course of absorption of heat-sterilized fibrinogen plastic is entirely comparable to that of heat-sterilized fibrin film. This is shown in Figure 2C where the progressive falling off of the absorption rate is clearly seen. The plastic also became surrounded by a thick fibrous capsule with a dry weight of about $10 \mathrm{mgm}$., but it retained less strength than the film, particularly in the latter stages of absorption where it fragmented badly. After 81 days only traces of the plastic could be detected.

Tryptic digestion of fibrin film. Results on the digestion by trypsin of variously heated fibrin films are summarized in Figure 5. The data are well represented by straight lines with the exception of the film heated for 1 minute at $100^{\circ} \mathrm{C}$. which disappears more rapidly during the first few minutes. Under these conditions the unmodified film shows a half digestion time of 16 to 18 minutes. A very brief exposure to heat (10 sec. at $100^{\circ} \mathrm{C}$.) increases this half time 3 -fold, to 54 minutes. Intense heat treatment, sufficient for sterilization, extends the half digestion time only by another factor of 3 , to 100 minutes.
During digestion the breaking strength of the film . progressively decreases. As is shown in Figure 6 this loss in strength is in general proportional to the loss in fibrin. This is in contrast

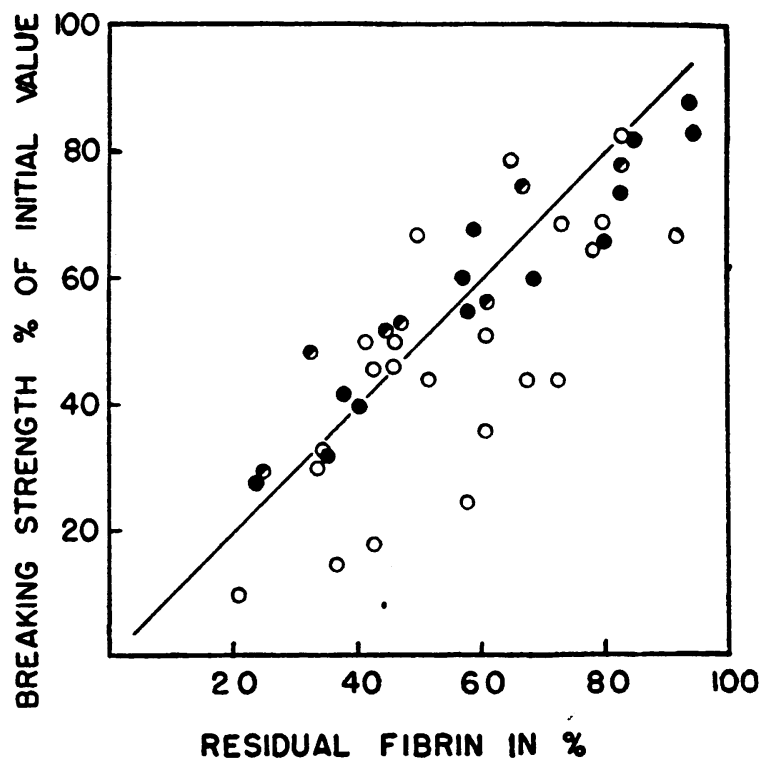

Fig. 6. The Breaking Strength of Fibrin Film Undergoing Tryptic Digestion as a Function of the Amount of Residual Fibrin

Symbols represent different series of measurements all performed with unheated film of initial weight of $16 \mathrm{mgm}$. per sq. $\mathrm{cm}$. 
to observations on the loss of tensile strength in vivo. The considerable scatter of the points reflects the dependence of this measurement on flaws in the film. The percentage of fibrin in the wet film becomes lower during digestion; thus the wet weight is reduced more slowly than the dry weight. This emphasizes the importance of using the latter as the measure of the proteolysis.

\section{DISCUSSION}

The wide range of absorption rates shown by the various types of film is seen in Figure 3 . The effect of heating is to increase progressively the resistance of the film. However, at $100^{\circ} \mathrm{C}$., the larger portion of this effect is obtained within the first minute and further heating, even for 10 times this period, makes the film only slightly more resistant. However, this additional treatment does increase the strength of the residual film. At the higher temperature of $120^{\circ} \mathrm{C}$. the absorption rate is reduced to $1 / 5$ that of the unmodified film.

Upon comparing films of different initial weight though of similar treatment (see Figure 1), one observes that the greater the thickness the greater the absorption rate. Indeed, the absorption rate in $m g m$. per day is roughly proportional to the initial weight. However, this means that the persistence time and the absorption rate in per cent per day should be nearly independent of the initial weight. Reference to Figure 1 shows the former to be true since, with a 3-fold difference in initial weights, the persistence times vary by a factor of only 1.2 to 1.3. This proportionality between the initial weight and the absorption rate suggests that proteolysis is occurring throughout the film rather than only at the surface. In the latter situation we would have expected different weights of film to show proportional persistence times and the same absorption rate in mgm. per day.

In this study only one thickness of heat-sterilized film was used so that similar deductions cannot be made regarding this material. However, in film sterilized by direct exposure to steam (11), tryptic digestion is more rapid in the thinner pieces. This would indicate that the enzyme is acting at the surface and that in this material the heat-imparted resistance could be accounted for, at least in part, by exclusion of the enzyme from the film interior.
In heat-sterilized film the absorption rate falls off steadily with time and the range of the changing values has been represented in Figure 3 by a vertical line. In Figure 4 this decrease in the rate of absorption is compared to the increasing encapsulation and it may be seen that there is a fairly good inverse correspondence between these 2 variables. This would suggest that this progressive decrease in the rate of absorption as these films remain in the body may be due merely to the formation of the fibrous capsule and not to any characteristic of the absorptive process.

The absorption of a protein structure in the body and its digestion in vitro both represent enzymatic proteolysis, and the 2 processes are therefore qualitatively similar. However, such enzymes may be quite specific and are very sensitive to the conditions under which they act (14). Extrapolation from an enzyme in one situation to a different enzyme in another situation should be made cautiously. In studies of the peptic digestion of collagen sutures Jenkins and Hrdina $(9,13)$ found, in general, a satisfactory correlation between the loss of strength in vitro and in vivo, but they noted that discrepancies sometimes occurred in which a suture, satisfactory by in vitro standards, disappeared too rapidly in the body.

TABLE I

\begin{tabular}{|c|c|c|c|c|}
\hline \multirow{3}{*}{ Treatment } & \multicolumn{4}{|c|}{ Time for half proteolysis } \\
\hline & \multicolumn{2}{|c|}{ In vitro } & \multicolumn{2}{|c|}{ In vivo } \\
\hline & $\min$. & $\frac{\text { heated }}{\text { unheated }}$ & days & $\frac{\text { heated }}{\text { unheated }}$ \\
\hline $\begin{array}{l}\text { Unmodified } \\
10 \text { sec. at } 100^{\circ} \mathrm{C} . \\
1 \text { min. at } 100^{\circ} \mathrm{C} . \\
10 \text { min. at } 100^{\circ} \mathrm{C} . \\
15 \text { min. at } 120^{\circ} \mathrm{C} \text {. } \\
1 \text { min. at } 155^{\circ} \mathrm{C} \text {. }\end{array}$ & $\begin{array}{r}19 \\
54 \\
84 \\
\\
156\end{array}$ & $\begin{array}{l}2.9 \\
4.4\end{array}$ & $\begin{array}{l}3.5 \\
4.6 \\
5.8 \\
48 \\
38\end{array}$ & $\begin{array}{c}1.32 \\
1.65 \\
13.7 \\
10.8\end{array}$ \\
\hline
\end{tabular}

A comparison of the effect of heat treatment on the digestion of fibrin film in vivo and in vitro reveals a similar picture; heat treatment increases the persistence in both situations but the quantitative relations are quite different. The half persistence times as measured by the 2 methods are summarized in Table 1, and it is seen that slight and moderate heat treatment prolongs the tryptic digestion time much more than the persistence in 
the body. On the other hand, in the heat-sterilized films the change is of the same order of magnitude.

The changes in the physical and chemical properties of fibrin film which accompany heat treatment have been carefully studied (11). The heated film has a higher water-equilibrated fibrin content, a lower opacity, a higher tensile strength, a lower swelling index in acid and alkali and a lower permeability. All of these physical changes may be attributed to the formation of additional permanent cross links in the fibrin network to yield a denser, more rigid structure. The decreased permeability which results may be of particular importance in increasing the resistance of the heated film to proteolytic enzymes both in vitro and in vivo. Thus, although the heat-sterilized film is completely impermeable to hemoglobin, for example, this protein passes freely through the unmodified film. If the action of the enzyme were thus restricted to the outer surface of the film, it would result in a much slower rate of proteolysis. Of course, the increased cross linking per se may also increase the resistance to enzymes. The chemical changes induced by the heat treatment, which are most strikingly shown in the change in affinity for acid and basic dyes, are undoubtedly associated with the physical changes and may be also involved in the increased persistence.

\section{SUMMARY}

The course of absorption of variously heated fibrin films, after implantation in rabbits, has been studied. A quantitative measure of absorption was obtained by measuring the actual weight of residual fibrin after different lengths of implantation. A measure of the tissue reaction to the implant was obtained by measuring similarly the weight of the surrounding fibrous capsule.

Persistence times ranged from less than 5 days for unmodified fibrin film to more than 80 days for heat-sterilized films. Intermediate persistence times were obtained by milder heat treatment. A heavy encapsulation of heat sterilized film occurred between 10 and 30 days following implantation.

The resistance of these variously heated films to tryptic digestion was measured and the responses in vivo and in vitro compared. The effect of heat treatment showed qualitative similarity but important quantitative differences were noted.

\section{BIBLIOGRAPHY}

1. Cohn, E. J., Blood proteins and their therapeutic value. Science, 1945, 101, 51; Blood and blood derivatives. American Scientist, 1945, 33, 61.

2. Ferry, J. D., and Morrison, P. R., Chemical, clinical, and immunological studies on the products of human plasma fractionation. XVI. Fibrin clots, fibrin films, and fibrinogen plastics. J. Clin. Invest., $1944,23,566$.

3. Ferry, J. D., and Morrison, P. R., Fibrin film and other plastic products from human plasma. Ind. and Eng. Chem., 1946, 38, 1217.

4. Ingraham, F. D., Bailey, O. T., and Cobb, C. A., Jr., The use of fibrin film as a dural substitute and in prevention of meningocerebral adhesions; further studies and clinical results. J. A. M. A., 1945, 128, 1088.

5. Singer, M., The combined use of fibrin film and clot in end-to-end union of nerves; experimental study. J. Neurosurg., 1945, 2, 102.

6. Bailey, O. T., and Ingraham, F. D., Chemical, clinical, and immunological studies on the products of human plasma fractionation. XXII. Fibrin films in neurosurgery, with special reference to their use in the repair of dural defects and in the prevention of meningocerebral adhesions. J. Clin. Invest., 1944, 23, 597.

7. Morrison, P. R., and Singer, M., Chemical, clinical, and immunological studies on the products of human plasma fractionation. XVII. A note on the absorption rates of fibrin films in tissue. J. Clin. Invest., 1944, 23, 573.

8. Kraissl, C. J., and Meleney, F. L., A method for determining the time of catgut digestion in vitro. Surg., Gynec. \& Obst., 1934, 59, 161.

9. Jenkins, H. P., and Hrdina, L. S., Absorption of surgical gut (catgut). II Pepsin digestion tests for evaluation of duration of tensile strength in the tissues. Arch. Surg., 1942, 44, 984.

10. Ferry, J. D., and Morrison, P. R., Preparation and properties of serum and plasma proteins. IX. Human fibrin in the form of an elastic film. J. Am. Chem. Soc., 1947, 69, 400.

11. Ferry, J. D., Singer, M., Morrison, P. R., Porsche, J. D., and Kutz, R. L., Preparation and properties of serum and plasma proteins. X. Modification of the physical and chemical properties of fibrin film by heat treatment. J. Am. Chem. Soc., 1947, 69, 409.

12. Hawn, C. v. Z., Bering, E. A., Jr., Bailey, O. T., and Armstrong, S. H., Jr., Chemical, clinical, and immunological studies on the products of human plasma fractionation. XIX. A note on the use of fibrinogen and thrombin in the surface treatment of burns. J. Clin. Invest., 1944, 23, 580.

13. Jenkins, H. P., and Hrdina, L. S., Absorption of surgical gut (catgut). I. The decline in tensile strength in the tissues. Arch. Surg., 1942, 44, 881.

14. See, for example, Northrop, J. H., Crystalline Enzymes. Columbia Univ. Press, New York, 1939. 